\title{
Interleukin-1 Antagonism Decreases Cortisol Levels in Obese Individuals
}

\author{
Sandrine Andrea Urwyler, ${ }^{1,2}$ Philipp Schuetz, ${ }_{1,2}^{2,3}$ Fahim Ebrahimi, ${ }^{1,2}$ \\ Marc Y. Donath, ${ }^{1,2}$ and Mirjam Christ-Crain ${ }^{1,2}$ \\ ${ }^{1}$ Department of Endocrinology, Diabetology and Metabolism, University Hospital Basel, $\mathrm{CH}-4031$ \\ Basel, Switzerland; '2Department of Clinical Research, University Hospital Basel, CH-4031 Basel, Switzerland; \\ and ${ }^{3}$ Department of Endocrinology, Medical University Clinic, Kantonsspital Aarau, CH-5001 Aarau, Switzerland
}

\begin{abstract}
Context: Increased cortisol levels in obesity may contribute to the associated metabolic syndrome. In obesity, the activated innate immune system leads to increased interleukin (IL)-1 $\beta$, which is known to stimulate the release of adrenocorticotropin hormone (ACTH).
\end{abstract}

Objectives: We hypothesized that in obesity IL-1 antagonism would result in downregulation of the hypothalamo-pituitary-adrenal axis, leading to decreased cortisol levels.

Design and Participants: In this prospective intervention study, we included 73 patients with obesity (body mass index $[\mathrm{BMI}] \geq 30 \mathrm{~kg} / \mathrm{m}^{2}$ ) and at least one additional feature of the metabolic syndrome.

Outcome Measures: The primary end point was change in morning cortisol from baseline to after the administration of the IL-1 receptor antagonist (anakinra/Kineret $\Theta$, total dose $3 \times 100 \mathrm{mg}$ ). Secondary end points were effects on salivary cortisol and ACTH.

Results: Median age was 56 years, $50.7 \%$ of patients were female, and median BMI was $36.3 \mathrm{~kg} / \mathrm{m}^{2}$. Median morning serum cortisol levels ( $\mathrm{nmol} / \mathrm{L}$ ) decreased significantly after IL-1 antagonism [from baseline, 452 to 423 ; absolute difference, $-38.7 ; 95 \%$ confidence interval $(\mathrm{Cl}),-64$ to $-13.4 ; P=0.0019$ ]. Similar effects were found for salivary cortisol levels $(-2.8 ; 95 \% \mathrm{Cl},-4.4$ to $-1.3 ; P=0.0007)$, ACTH levels $(-2.2 ; 95 \% \mathrm{Cl} ;-4.2$ to $-0.1 ; P=0.038)$, systolic blood pressure $(-5.2,95 \% \mathrm{Cl},-8.5$ to $-1.8 ; P=0.0006)$, and heart rate $(-2.9 ; 95 \% \mathrm{Cl},-4.7$ to $-1.0 ; P=0.0029)$.

Conclusion: IL-1 antagonism in obese individuals with features of the metabolic syndrome leads to a decrease in serum cortisol, salivary cortisol, and ACTH levels along with a reduction in systolic blood pressure and heart rate. (J Clin Endocrinol Metab 102: 1712-1718, 2017)

O besity is a worldwide pandemic, associated with a high prevalence of comorbidities, leading to the metabolic syndrome $(1,2)$. New treatment strategies are warranted to prevent obesity-related comorbidities and improve their treatment.

Data about cortisol levels in obesity are conflicting (3). Whereas some studies have reported normal baseline cortisol levels and higher urinary cortisol levels resulting from an increased degradation upon an enhanced $11 \beta$-hydroxysteroid dehydrogenase type 1 activity (4), other studies have reported increased baseline cortisol levels in patients

ISSN Print 0021-972X ISSN Online 1945-7197

Printed in USA

Copyright (c) 2017 Endocrine Society

Received 14 December 2016. Accepted 15 February 2017

First Published Online 20 February 2017 with central obesity resulting from an overactivated hypothalamo-pituitary-adrenal (HPA) axis $(3,5,6)$ and a positive association of cortisol with visceral fat accumulation (7). In patients with the metabolic syndrome, cortisol levels were even higher, according to the amount of the underlying metabolic features $(8,9)$. Elevated cortisol levels as seen in Cushing syndrome are known to be associated with a metabolic dysregulation and diabetes eventually leading to cardiovascular mortality (10-12).

Obesity leads to a pathological activation of the innate immune system characterized by changes in cytokines,

\footnotetext{
Abbreviations: $\mathrm{ACTH}$, adrenocorticotropin hormone; $\mathrm{BMl}$, body mass index; $\mathrm{Cl}$, confidence interval; CLIA, electrochemiluminescence immunoassay; CRP, C-reactive protein; ECLIA, electroelectrochemiluminescence immunoassay; FSH, follicle-stimulating hormone; HPA, hypothalamo-pituitary-adrenal; IL, interleukin; IQR, interquartile range; LH, luteinizing hormone; TSH, thyrotropin.
} 
chemokines, and the number and activation state of various leukocyte populations (13). As a result, interleukin- $1 \beta$ (IL- $1 \beta$ ) seems to play a central role. Indeed, IL- $1 \beta$ production is increased in several tissues, including the hypothalamus (14-16). After weight loss by lifestyle interventions (17) or bariatric surgery $(18,19), \mathrm{IL}-1 \beta$ and IL-1 $\beta$-dependent inflammatory factors such as leukocytes, C-reactive protein (CRP), and IL-6 decrease. Clinical studies have shown that IL-1 antagonism may improve insulin secretion or sensitivity and glycemia in obese individuals as well as in patients with type 2 diabetes (20). However, it is unknown whether these effects are associated with changes in the activation of the HPA axis.

Previous studies have evaluated the interaction between the immune and neuroendocrine systems, showing that several cytokines have stimulatory effects on the HPA axis (21). In particular, IL- $1 \beta$ appears to have a strong stimulatory effect on adrenocorticotropin hormone (ACTH) secretion in rodents (22-24). This was explained by the colocalization of IL-1 and corticotropinreleasing hormone producing cells in the hypothalamus $(25,26)$ but also by a direct stimulatory effect of IL-1 on the ACTH-producing cells at the level of the pituitary (23, 27, 28). Furthermore, a direct effect on cortisol production in the adrenal glands was reported $(27,29)$. Similarly, in lean, healthy humans, the intravenous or subcutaneous administration of IL- $1 \beta$ led to elevated plasma ACTH and cortisol levels $(27,30,31)$.

Based on this information, we hypothesized that the activation of the IL-1 system observed in some obese individuals may stimulate the HPA axis and therefore that IL-1 antagonism would decrease ACTH and cortisol levels in these individuals.

\section{Methods}

\section{Study design}

This prospective, open-labeled, interventional study involved 76 patients with obesity and at least one additional feature of the metabolic syndrome. All patients were recruited at the University Hospital Basel from October 2014 to January 2016 and received a total of five injections of a recombinant human IL-1 receptor antagonist (100 mg of anakinra/Kineret $\left.{ }^{\circledR}\right)$ within 3 days. The consecutive injections were started at $8 \mathrm{PM}$ and continued in 12-hour intervals (Figure 1).

\section{Patients}

The study was conducted according to the ethical guidelines of the Declaration of Helsinki and the applicable International Conference on Harmonization guidelines on good clinical practice. The local ethical committee approved the study. Written informed consent was obtained from all patients.

Inclusion criteria were age between 18 and 80 years, body mass index $(\mathrm{BMI}) \geq 30 \mathrm{~kg} / \mathrm{m}^{2}$, and at least one of the following additional features of the metabolic syndrome: hyperglycemia (hemoglobin $\mathrm{A} 1 \mathrm{c} \geq 5.7 \% / 39 \mathrm{mmol} / \mathrm{mol}$ ), hypertension (blood pressure $\geq 130 / 85 \mathrm{~mm} \mathrm{Hg}$ or treatment of hypertension), or dyslipidemia (high-density lipoprotein $<1.0 \mathrm{mmol} / \mathrm{L}$ or triglycerides $\geq 1.7 \mathrm{mmol} / \mathrm{L}$ or low-density lipoprotein $>3.4 \mathrm{mmol} / \mathrm{L}$ or lipid-lowering treatment). Exclusion criteria were medication with glucocorticoids, known Cushing syndrome, chronic inflammatory disease, history of a severe infection within the previous 2 months or an acute infection, severe hematologic, kidney (creatinine clearance $<30 \mathrm{~mL} / \mathrm{min}$ ) or liver disease (transaminases more than four times the upper normal range), cancer, history of tuberculosis, chronic alcohol abuse, pregnancy, or breastfeeding.

\section{Study procedures}

All patients attended a screening visit in which a study doctor checked medical records and performed blood sampling and a physical examination.

The study sequence consisted of four study visits taking place within 2 weeks for each patient. All visits were scheduled between 7:30 AM and 10 AM after an overnight fast. To not confound cortisol values by circadian rhythm, study visits for every participant were consistently scheduled at the same time. At each of these four visits, clinical parameters were assessed and blood and salivary samples were taken.

At the first visit (baseline visit) a body impedance analysis was performed. The following day, patients attended the second study visit (dexa only) after a 1-mg dexamethasone suppression test (intake of $1 \mathrm{mg}$ dexamethasone Galepharm ${ }^{\circledR}$ orally at midnight). Between visits two and three, there was a "washout" period of 7 days.

After three injections of anakinra within 2 days, patients attended the third study visit (anakinra only visit) and came the following day for visit four (anakinra plus dexa, with two additional injections of anakinra and intake of $1 \mathrm{mg}$ dexamethasone Galepharm ${ }^{\circledR}$ at midnight). For the detailed study schedule, see Fig. 1.

\section{Laboratory values}

Cortisol was measured with an electrochemiluminescence immunoassay (CLIA; Elecsys cortisol test; Roche Diagnostics $\mathrm{GmbH}$, Mannheim, Germany) with an intra-assay coefficient of variation of $1.0 \%$ to $1.7 \%$ and interassay coefficient of variation of $1.4 \%$ to $2.8 \%$. Salivary cortisol was collected with Salivette ${ }^{\circledR}$ Cortisol (article number 51.1534.500; Sarstedt AG \& Co., Nümbrecht, Germany). All laboratory analyses were conducted at central laboratories at University Hospital Basel. 
IL-6 was measured with CLIA (Elecsys IL-6 test; Roche Diagnostics $\mathrm{GmbH}$ ) with a reference range $<7 \mathrm{pg} / \mathrm{mL}$. CRP was determined with an immunoturbidimetric assay (Tina-quant C-Reactive Protein Gen. 3 Test; Roche Diagnostics GmbH). ACTH was quantified with a CLIA (ACTH Immulite; Siemens Health Care Diagnostics Products Ltd., Gwynedd, UK), with a reference range $<46.0 \mathrm{pg} / \mathrm{mL}$. Prolactin was determined with an electro-CLIA (ECLIA) (Elecsys Prolactin II test; Roche Diagnostics $\mathrm{GmbH}$ ), thyrotropin (TSH) was measured with an ECLIA (Elecsys TSH test; Roche Diagnostics GmbH). Human growth hormone was quantified with a CLIA (Immunlite 2000 hGH; Siemens Health Care Diagnostics Products Ltd.). Luteinizing hormone $(\mathrm{LH})$ and follicle-stimulating hormone (FSH) were determined with an ECLIA (Elecsys LH and FSH Test; Roche Diagnostics GmbH).

\section{Study end points}

The predefined primary end point was change in serum morning cortisol levels from baseline to after three injections of anakinra (visit 3). Predefined secondary end points were change in salivary cortisol and ACTH from baseline to after anakinra, changes of CRP and IL-6, and change in serum cortisol levels between a 1-mg dexamethasone suppression test and 1-mg dexamethasone suppression test plus additional administration of anakinra. A further secondary end point was the prediction of inflammatory markers (i.e., IL-6 and CRP) and body composition measurements (e.g., $\mathrm{BMI})$ on treatment response to anakinra.

\section{Power calculation and statistical analysis}

Our sample size calculation was based on the assumption that morning cortisol levels would decline from $500 \mathrm{nmol} / \mathrm{L}$ (standard deviation \pm 90 ) to $450 \mathrm{nmol} / \mathrm{L}$ upon antagonizing IL-1 with anakinra. Sixty-nine participants were needed to give this study a power of $80 \%$ to show a significant difference in morning cortisol levels using a paired $t$ test. Assuming a lost to follow-up rate of $10 \%$, we aimed to include a total of 76 patients.

Discrete variables are expressed as counts (percentage) and continuous variables as medians and interquartile ranges (IQRs) unless stated otherwise. For two-group comparison with paired data, we used a Wilcoxon test. We used linear regression models to estimate treatment response of anakinra on changes $(\Delta)$ in serum cortisol, salivary cortisol, and ACTH levels before and after treatment of different predefined predictors (i.e., median IL-6 levels, CRP levels, statin use, BMI, waist circumference, age, sex, diabetes, hypertension, low-density lipoprotein cholesterol).

Testing was two-tailed, and $P<0.05$ was considered statistically significant. For statistical analysis, we used GraphPad Prism®, version 6.0, for Mac (GraphPad Software, La Jolla, CA) and STATA 12.1 (Stata Corp, College Station, TX).

\section{Results}

\section{Baseline characteristics}

In total, 212 patients were prescreened. Of these, 136 did not fulfill the eligibility criteria or denied participation. Seventy-six patients were included in the study, but three of these patients did not complete the study: two patients withdrew informed consent after the screening visit and one patient was excluded before receiving the study medication because he suffered an acute cardiac decompensation needing hospitalization. Seventy-three patients received the study medication and completed the trial (Fig. 2).

The median age of the 73 patients was 56 years ( 48 to 63), median BMI was $36.3 \mathrm{~kg} / \mathrm{m}^{2}$ (33.3 to 40.9 ), $50.7 \%$ were female, $64.4 \%$ of the patients had a type 2 diabetes mellitus, $21.9 \%$ suffered from impaired glucose tolerance, $76.7 \%$ from hypertension, and $79.5 \%$ from dyslipidemia. A complete description of the baseline characteristics is given in Table 1.

\section{Effects of IL-1 antagonism on the HPA axis}

Morning serum cortisol levels decreased upon IL-1 antagonism from median (IQR) $452 \mathrm{nmol} / \mathrm{L}(374 ; 549)$ at baseline to $423 \mathrm{nmol} / \mathrm{L}(337 ; 491)$ after three injections of anakinra [absolute difference, $-38.7 ; 95 \%$ confidence interval (CI), -64 to $-13.4 ; P<0.01$ ]. Salivary cortisol levels decreased from $19.2 \mathrm{nmol} / \mathrm{L}(15 ; 25.5)$ to $15.5 \mathrm{nmol} / \mathrm{L}(11.9,23.7)$ (absolute difference, -2.8; $95 \% \mathrm{CI},-4.4$ to $-1.3 ; P<0.001)$, and ACTH levels from $26.4 \mathrm{pg} / \mathrm{mL}(19.5 ; 32.9)$ to $23.7 \mathrm{pg} / \mathrm{mL}(19 ; 33.2)$ (absolute difference, $-2.2 ; 95 \% \mathrm{CI},-4.2$ to $-0.1 ; P=0.038)$, respectively. In contrast, there was no change in serum cortisol levels after the 1-mg dexamethasone suppression test and the dexamethasone suppression test plus IL-1 antagonism [28 nmol/L $(19 ; 45)$ and $27.5 \mathrm{nmol} / \mathrm{L}(20$; 45), $P=0.17$ ] [Fig. 3(a-c)].

There was no change in other pituitary hormones (i.e., $\mathrm{LH}, \mathrm{FSH}, \mathrm{TSH}$, growth hormone, and prolactin) upon IL-1 antagonism. As expected, there was a decrease of inflammatory parameters (leukocytes, neutrophile granulocytes, CRP, and IL- 6 upon IL-1 antagonism) (Table 2). 


\section{Table 1. Baseline Characteristics of All Patients}

$\mathbf{n}=73$

\begin{tabular}{|c|c|}
\hline Age, y & $56(48 ; 63)$ \\
\hline BMI, $\mathrm{kg} / \mathrm{m}^{2}$ & $36.3(33.3 ; 40.9)$ \\
\hline Weight, kg & $106(96 ; 123)$ \\
\hline Female & $37(50.7 \%)$ \\
\hline Caucasian & $68(93.2 \%)$ \\
\hline Current smoker & $13(17.8 \%)$ \\
\hline Diabetes mellitus type 2 & $47(64.4 \%)$ \\
\hline Impaired glucose tolerance & $16(21.9 \%)$ \\
\hline Arterial hypertension & $56(76.7 \%)$ \\
\hline Dyslipidemia & $58(79.5 \%)$ \\
\hline \multicolumn{2}{|l|}{ Comorbidities } \\
\hline Obstructive sleep apnea & $35(47.9 \%)$ \\
\hline Psychiatric diseases & $18(24.7 \%)$ \\
\hline Known hypothyreoidism & $11(15.1 \%)$ \\
\hline Known hypogonadism in men & $2(5.6 \%)$ \\
\hline \multicolumn{2}{|l|}{ Medication } \\
\hline Oral anidiabetic drugs & $39(53.4 \%)$ \\
\hline Insulin & $25(34.2 \%)$ \\
\hline GLP-1 analogon & $17(23.3 \%)$ \\
\hline Antihypertensive medication & $53(72.6 \%)$ \\
\hline Statin & $35(47.9 \%)$ \\
\hline NSAID & $4(5.5 \%)$ \\
\hline Antidepressant drugs & $11(15.1 \%)$ \\
\hline Antipsycotic drugs & $1(1.4 \%)$ \\
\hline Anticonvulsive medication & $4(5.5 \%)$ \\
\hline Thyroid hormone substitution & $11(15.1 \%)$ \\
\hline Testosterone Substitution & 2 \\
\hline Contraceptive pill & 1 \\
\hline \multicolumn{2}{|l|}{ Clinical features } \\
\hline Visceral obesity & $73(100 \%)$ \\
\hline Abdominal circumference, cm & $121(112 ; 131)$ \\
\hline Purple striae & $4(5.5 \%)$ \\
\hline Moon face & $20(27.4 \%)$ \\
\hline Buffalo hump & $27(37.0 \%)$ \\
\hline Hirsutism & $0(0 \%)$ \\
\hline Easy bruising & $0(0 \%)$ \\
\hline Facial plethora & $3(4.1 \%)$ \\
\hline Akne & $2(2.7 \%)$ \\
\hline \multicolumn{2}{|l|}{ Body impedance analysis } \\
\hline Fat mass, $\%$ of total body & $36(26 ; 42)$ \\
\hline Muscle mass, $\%$ of total body & $45(39 ; 53)$ \\
\hline Fat free mass, \% of total body & $64(58 ; 74)$ \\
\hline Body metabolic rate, kcal & $1900(1700 ; 2190)$ \\
\hline \multicolumn{2}{|l|}{ Laboratory values } \\
\hline $\operatorname{HbA1c}(\%)$ & $6.5(5.8 ; 8.2)$ \\
\hline Triglycerides (mmol/L) & $1.7(1.3 ; 2.5)$ \\
\hline Total cholesterol (mmol/L) & $4.6(3.6 ; 5.3)$ \\
\hline LDL-cholesterol (mmol/L) & $2.4(1.7 ; 3.1)$ \\
\hline HDL-cholesterol (mmol/L) & $1.1(0.9 ; 1.4)$ \\
\hline
\end{tabular}

Data are median (IQR) or number (\%), unless otherwise stated.

\section{Predictors of treatment response}

We also investigated treatment response to IL-1 antagonism in different subgroups [Supplemental Fig. $4(a-c)]$. As a result, high baseline IL-6 was an important predictor for a positive treatment response to IL-1 antagonism. Compared with patients with IL-6 levels below the median (i.e., $3.7 \mathrm{pg} / \mathrm{mL}$ ), patients with baseline IL- $6 \geq 3.7 \mathrm{pg} / \mathrm{mL}$ had a more pronounced decrease in salivary cortisol (mean difference, $-3.40 ; 95 \% \mathrm{CI},-6.49$ to $-0.31 ; P=0.03$ ) and in ACTH (mean difference, $-3.87 ; 95 \% \mathrm{CI},-7.93$ to $0.18 ; P=0.06)$. In contrast, CRP did not predict the IL-1 receptor antagonist treatment response (data not shown). Patients on statin therapy showed a poorer treatment response with regard to delta salivary cortisol levels compared with patients without statin treatment (mean difference, 3.02; 95\% CI, -0.01 to $6.13 ; P=0.057)$.

A BMI lower than the median (i.e., $36.6 \mathrm{~kg} / \mathrm{m}^{2}$ ) was associated with a more pronounced effect on delta serum cortisol levels (mean difference 48.0; 95\% CI, -1.65

\section{(a) Serum cortisol levels before and after anakinra}

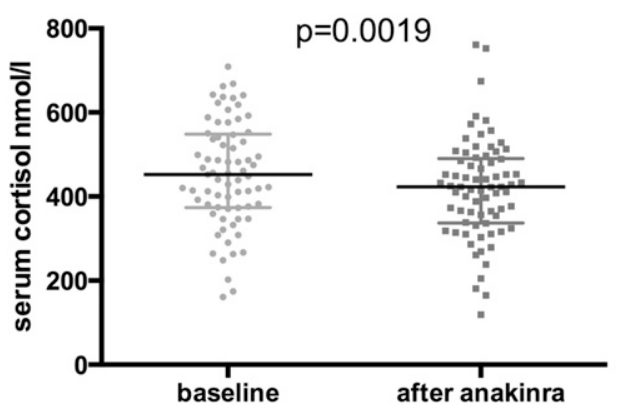

(b) Salivary cortisol levels before and after anakinra

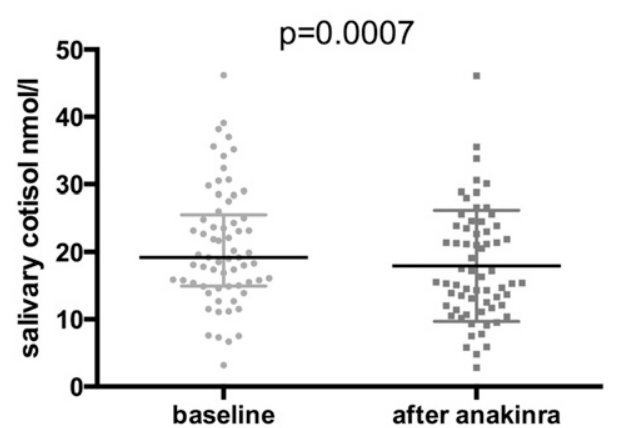

(c) АCTH levels before and after anakinra

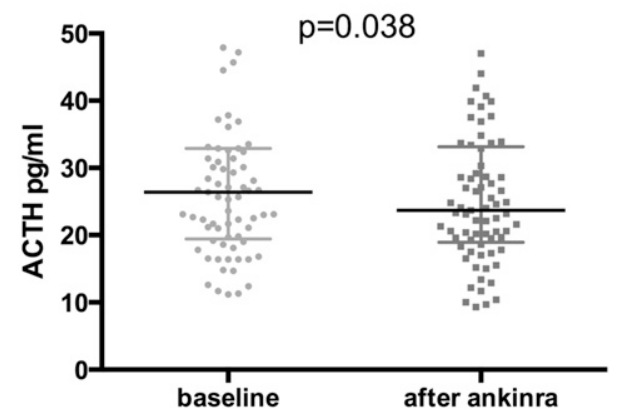

Figure 3. Comparison of serum cortisol, salivary cortisol, and ACTH levels before and after IL-1 antagonism. Comparisons of baseline serum cortisol (a), salivary cortisol (b), and ACTH levels (c) with their equivalent after short-term treatment with anakinra using a Wilcoxon test. 
Table 2. Effect of Anakinra

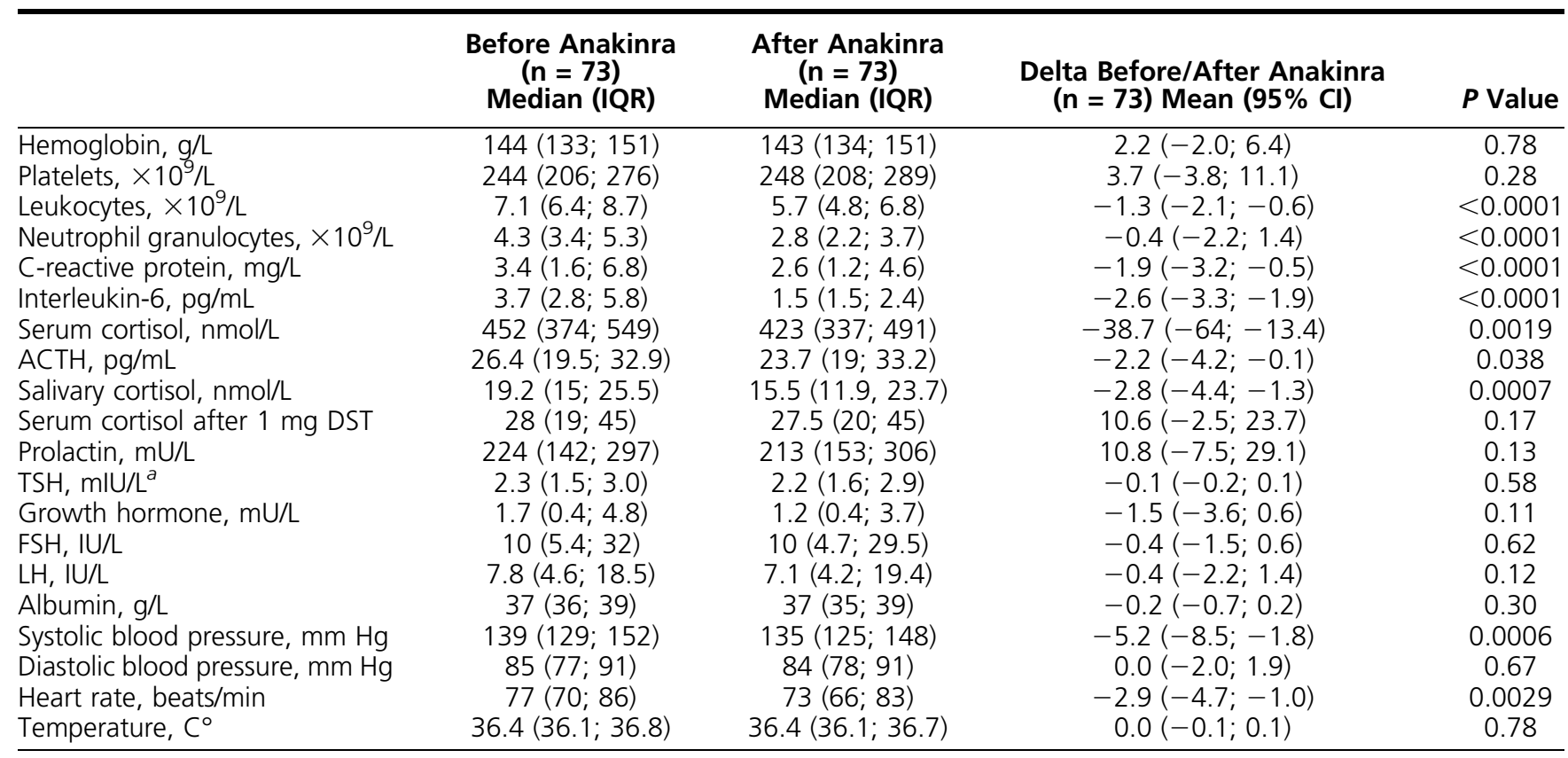

Data are expressed as median (IQR) or number $(\%)$ and absolute differences in mean $(95 \% \mathrm{Cl})$ unless stated otherwise. $P$ values were assessed using the Wilcoxon test.

${ }^{a}$ Only 62 patients without thyroid hormone substitution were included.

to $97.7 ; P=0.06)$. Conversely, a higher percentage of body fat mass [above median (i.e., 36\%)] tended to be associated with a better treatment response concerning delta serum cortisol (mean difference, $-36.45 ; 95 \% \mathrm{CI}$, -86.80 to $13.89 ; P=0.15$ ). We did not find a more pronounced effect in the subgroup of obese patients with a psychiatric diagnosis $(\mathrm{n}=18)$ (data not shown).

\section{Side effects/adverse events}

No patient withdrew from the study because of drugrelated adverse events. There were no severe and no unexpected adverse events related to the study drug anakinra, especially no neutropenia. Main side effects were mild headache $(\mathrm{n}=10)$ and mild transient injection site reaction such as pain and local reddening $(\mathrm{n}=10)$. Three patients developed an exanthema 7 to 10 days after the first injection of anakinra, with a complete resolution after a maximum of 3 weeks. All reported adverse events are listed in Table 3.

\section{Discussion}

The main finding of this study is that IL-1 antagonism leads to an inhibition of the HPA axis decrease in ACTH and cortisol levels as well as a decrease in systolic blood pressure and heart rate in obese individuals with at least one additional feature of the metabolic syndrome. This suggests a direct interaction between the pathologic activation of the innate immune system and stimulation of the HPA axis in obesity. The inhibition of the HPA axis upon IL-1 antagonism seems to depend on the extent of inflammation. It was especially pronounced in patients with a high inflammatory state (i.e., high IL-6) and was reduced in patients on statin therapy, which is known to have anti-inflammatory effects (32).

IL-1 antagonism has been shown to improve glucose metabolism (33) and is currently under investigation in the Cardiovascular Risk Reduction Study (Reduction in Recurrent Major CV Disease Events) (CANTOS) Trial (NCT01327846) as an anti-inflammatory agent for secondary prevention of cardiovascular disease and new onset or progression of type 2 diabetes in patients with recent myocardial infarction (34). Our data add a possible mechanism of how IL-1 antagonists may improve glucose metabolism and thus reduce cardiovascular risk.

\section{Table 3. Adverse Events Associated With Anakinra/Kineret®}

\begin{tabular}{lc}
\hline & $\mathbf{N}=\mathbf{7 3}$ \\
\hline Mild transient injection site reactions & $10(13.6 \%)$ \\
Exanthema & $3(4.1 \%)$ \\
Mild headache & $10(13.6 \%)$ \\
Nausea & $1(1.4 \%)$ \\
Malaise & $3(4.1 \%)$ \\
Vertigo & $5(6.8 \%)$ \\
\hline
\end{tabular}

Data are number (\%).There were no severe and no unexpected adverse events related to the study drug anakinra, especially no neutropenia. 
Although the magnitude of the effects is mild, this may still have profound consequence over the years. Moreover, cortisol levels might be a predictor for treatment response of IL-1 antagonism in diabetic patients.

Notably, we found an important decrease in systolic blood pressure and heart rate upon IL-1 antagonism. To our knowledge, this effect of IL-1 antagonism has not yet been described in humans; however, in rodents, it has been reported that IL-1 antagonism attenuated hypertension. The authors postulated a mechanism via salt retention in the kidney, which is regulated by a nitric oxide-dependent mechanism (35). Our data suggest an additional effect via cortisol, which is known to increase blood pressure. We speculate that the decrease in heart rate might be explained by the permissive effect of glucocorticoids on catecholamines (36). As a result, the decrease of cortisol levels upon IL-1 antagonism might lead to a decline in the action of catecholamines and to a negative chronotropic effect. This finding might point to a causal treatment approach of IL-1 antagonism for arterial hypertension via reduction of cortisol levels.

The inhibition of the HPA axis upon IL-1 antagonism seems to depend on the extent of activation of the innate immune system. Patients with high IL-6 levels had a better treatment response, whereas patients on statins showed a less pronounced effect. In contrast and unexpectedly, BMI was a negative predictor for treatment response. It is possible that the underlying mechanism of treatment is a dose-dependent effect of the study drug, anakinra, with a reduced effect in patients with increased body volume. Increased body fat mass, in contrast, was associated with a more pronounced treatment effect, suggesting that the stimulatory effect on the HPA axis via inflammation is dependent on the amount of adipose tissue in obese individuals.

That there was not only an effect of IL-1 antagonism on cortisol levels, but also on ACTH levels, suggests a central effect on the HPA axis via hypothalamus or the pituitary gland. An additional direct effect on the adrenal glands is also possible.

There was no difference in cortisol levels after the 1-mg dexamethasone suppression test only in comparison with the 1-mg dexamethasone suppression test plus IL-1 antagonism. It is possible that dexamethasone, with its strong immunosuppressive properties, overrode the effect of IL-1 antagonism. In addition, the chronic inflammation state of obesity involves different cytokines. Dexamethasone might have a broader effect on other cytokines possibly involved in the stimulation of the HPA axis.

Apart from the HPA axis, we found no effect of IL-1 antagonism on other pituitary hormones. IL-1 has been reported to have an inhibitory effect on growth hormone, $\mathrm{TSH}, \mathrm{LH}$, and FSH in vitro and in rats (37). However, we are not aware of data evaluating effects of IL-1 antagonism on pituitary hormones in humans. The lack of effect of IL-1 antagonism on other pituitary hormones in our trial might be due to the rather short treatment duration.

Our study has limitations. First, the study was not conducted as a randomized placebo-controlled, but rather as a prospective open-label, trial. However, we investigated robust end points, and the observed antiinflammatory effects of anakinra, which correlated with the decrease in cortisol, are unlikely from "placebo effects." Second, patients had only a short treatment exposure of three injections of anakinra. It is possible that longer treatment duration would have resulted in a more pronounced treatment effect. In line with this reasoning, improvement of glucose metabolism upon IL-1 antagonism requires several weeks of treatment to reach a maximal effect (20).

We herein show that IL-1 antagonism in obese patients reduced the overactivated HPA axis leading to a decrease in ACTH and cortisol levels as well as a decrease in systolic blood pressure and heart rate. If our findings are confirmed in a placebo-controlled, double-blind study, IL-1 antagonism could be a treatment option to improve cortisol levels in obesity and thereby prevent metabolic and cardiovascular complications.

\section{Acknowledgments}

We thank all patients for their participation in this study, the staff of the laboratory and the Department of Endocrinology, Diabetology \& Metabolism of University Hospital Basel, and our study nurses for their most helpful support during the study, especially Cemile Bathelt and Nina Hutter.

Address all correspondence to: Sandrine Urwyler, MD, University Hospital, Petersgraben 4, CH-4031 Basel, Switzerland. E-mail: sandrine.urwyler@usb.ch.

This work was supported by the Swiss National Foundation (Grant no. PP00P3-12346) (to M.C.-C.), the "Wissenschaftspool 2014" of the University Hospital Basel (to S.A.U.), and the University of Basel (Nachwuchsförderung 2015) (to S.A.U.). The funding sources were neither involved in the design of the study nor in writing of the manuscript. The authors have no conflicts of interest to declare.

Author contributions: S.A.U., P.S., M.Y.D., and M.C.-C. designed the study. S.A.U. recruited the participating patients; S.A.U. and P.S. did the statistical analyses; S.A.U., P.S., M.Y.D., and M.C.-C. interpreted the data; and S.A.U., P.S., F.E., M.Y.D., and M.C.-C. were involved in the writing of the manuscript.

Clinical trial registry: ClinicalTrials.gov no. NCT02227420 (registered 26 August 2014).

Disclosure Summary: The authors have nothing to disclose. 


\section{References}

1. Flegal KM, Graubard BI, Williamson DF, Gail MH. Cause-specific excess deaths associated with underweight, overweight, and obesity. JAMA. 2007;298(17):2028-2037.

2. World Health Organization. Fact sheet No 311, obesity and overweight (online). http://www.who.int/mediacentre/factsheets/ fs311/en/.Accessed 21 February 2017.

3. Abraham SB, Rubino D, Sinaii N, Ramsey S, Nieman LK. Cortisol, obesity, and the metabolic syndrome: a cross-sectional study of obese subjects and review of the literature. Obesity (Silver Spring). 2013;21(1):E105-E117.

4. Dunkelman SS, Fairhurst B, Plager J, Waterhouse C. Cortisol metabolism in obesity. J Clin Endocrinol Metab. 1964;24: 832-841.

5. Müssig K, Remer T, Maser-Gluth C. Brief review: glucocorticoid excretion in obesity. J Steroid Biochem Mol Biol. 2010;121(3-5): 589-593.

6. Pasquali R, Vicennati V, Cacciari M, Pagotto U. The hypothalamicpituitary-adrenal axis activity in obesity and the metabolic syndrome. Ann N Y Acad Sci. 2006;1083:111-128.

7. Mårin P, Darin N, Amemiya T, Andersson B, Jern S, Björntorp P. Cortisol secretion in relation to body fat distribution in obese premenopausal women. Metabolism. 1992;41(8):882-886.

8. Anagnostis P, Athyros VG, Tziomalos K, Karagiannis A, Mikhailidis DP. Clinical review: The pathogenetic role of cortisol in the metabolic syndrome: a hypothesis. J Clin Endocrinol Metab. 2009;94(8):2692-2701.

9. Reinehr T, Kulle A, Wolters B, Knop C, Lass N, Welzel M, Holterhus PM. Relationships between 24-hour urinary free cortisol concentrations and metabolic syndrome in obese children. J Clin Endocrinol Metab. 2014;99(7):2391-2399.

10. An K, Salyer J, Brown RE, Kao HF, Starkweather A, Shim I. Salivary biomarkers of chronic psychosocial stress and CVD risks: a systematic review. Biol Res Nurs. 2016;18(3):241-263.

11. Manenschijn L, Schaap L, van Schoor NM, van der Pas S, Peeters GM, Lips P, Koper JW, van Rossum EF. High long-term cortisol levels, measured in scalp hair, are associated with a history of cardiovascular disease. J Clin Endocrinol Metab. 2013;98(5):2078-2083.

12. Neary NM, Booker OJ, Abel BS, Matta JR, Muldoon N, Sinaii N, Pettigrew RI, Nieman LK, Gharib AM. Hypercortisolism is associated with increased coronary arterial atherosclerosis: analysis of noninvasive coronary angiography using multidetector computerized tomography. J Clin Endocrinol Metab. 2013;98(5):2045-2052.

13. Donath MY, Shoelson SE. Type 2 diabetes as an inflammatory disease. Nat Rev Immunol. 2011;11(2):98-107.

14. Donath MY, Dalmas É, Sauter NS, Böni-Schnetzler M. Inflammation in obesity and diabetes: islet dysfunction and therapeutic opportunity. Cell Metab. 2013;17(6):860-872.

15. Ballak DB, Stienstra R, Tack CJ, Dinarello CA, van Diepen JA. IL-1 family members in the pathogenesis and treatment of metabolic disease: Focus on adipose tissue inflammation and insulin resistance. Cytokine. 2015;75(2):280-290.

16. Di Renzo L, Bigioni M, Del Gobbo V, Premrov MG, Barbini U, Di Lorenzo N, De Lorenzo A. Interleukin-1 (IL-1) receptor antagonist gene polymorphism in normal weight obese syndrome: relationship to body composition and IL-1 alpha and beta plasma levels. Pharmacol Res. 2007;55(2):131-138.

17. Chae JS, Paik JK, Kang R, Kim M, Choi Y, Lee SH, Lee JH. Mild weight loss reduces inflammatory cytokines, leukocyte count, and oxidative stress in overweight and moderately obese participants treated for 3 years with dietary modification. Nutr Res. 2013;33(3):195-203.

18. Cottam DR, Mattar SG, Barinas-Mitchell E, Eid G, Kuller L, Kelley DE, Schauer PR. The chronic inflammatory hypothesis for the morbidity associated with morbid obesity: implications and effects of weight loss. Obes Surg. 2004;14(5):589-600.

19. Dalmas E, Rouault C, Abdennour M, Rovere C, Rizkalla S, Bar-Hen A, Nahon JL, Bouillot JL, Guerre-Millo M, Clément K,
Poitou C. Variations in circulating inflammatory factors are related to changes in calorie and carbohydrate intakes early in the course of surgery-induced weight reduction. Am J Clin Nutr. 2011;94(2): 450-458.

20. Donath MY. Targeting inflammation in the treatment of type 2 diabetes: time to start. Nat Rev Drug Discov. 2014;13(6):465-476.

21. McCann SM, Kimura M, Karanth S, Yu WH, Mastronardi CA, Rettori V. The mechanism of action of cytokines to control the release of hypothalamic and pituitary hormones in infection. Ann N Y Acad Sci. 2000;917:4-18.

22. van der Meer MJ, Sweep CG, Rijnkels CE, Pesman GJ, Tilders FJ, Kloppenborg PW, Hermus AR. Acute stimulation of the hypothalamic-pituitary-adrenal axis by IL-1 beta, TNF alpha and IL-6: a dose response study. J Endocrinol Invest. 1996;19(3): 175-182.

23. Woloski BM, Smith EM, Meyer WJ III, Fuller GM, Blalock JE. Corticotropin-releasing activity of monokines. Science. 1985; 230(4729):1035-1037.

24. Yasin S, Costa A, Navarra P, Pozzoli G, Kostoglou-Athanassiou I, Forsling M, Grossman A. Endothelin-1 stimulates the in vitro release of neurohypophyseal hormones, but not corticotropinreleasing hormone, via ETA receptors. Neuroendocrinology. 1994;60(6):553-558.

25. Goshen I, Yirmiya R. Interleukin-1 (IL-1): a central regulator of stress responses. Front Neuroendocrinol. 2009;30(1):30-45.

26. Navarra P, Tsagarakis S, Faria MS, Rees LH, Besser GM, Grossman AB. Interleukins- 1 and -6 stimulate the release of corticotropin-releasing hormone- 41 from rat hypothalamus in vitro via the eicosanoid cyclooxygenase pathway. Endocrinology. 1991; 128(1):37-44.

27. Turnbull AV, Rivier CL. Regulation of the hypothalamic-pituitaryadrenal axis by cytokines: actions and mechanisms of action. Physiol Rev. 1999;79(1):1-71.

28. Bernton EW, Beach JE, Holaday JW, Smallridge RC, Fein HG. Release of multiple hormones by a direct action of interleukin- 1 on pituitary cells. Science. 1987;238(4826):519-521.

29. Besedovsky HO, del Rey A. Immune-neuro-endocrine interactions: facts and hypotheses. Endocr Rev. 1996;17(1):64-102.

30. Crown J, Jakubowski A, Kemeny N, Gordon M, Gasparetto C, Wong G, Sheridan C, Toner G, Meisenberg B, Botet J. A phase I trial of recombinant human interleukin-1 beta alone and in combination with myelosuppressive doses of 5 -fluorouracil in patients with gastrointestinal cancer. Blood. 1991;78(6):1420-1427.

31. Curti BD, Urba WJ, Longo DL, Janik JE, Sharfman WH, Miller LL, Cizza G, Shimizu M, Oppenheim JJ, Alvord WG, Smith JW, 2nd. Endocrine effects of IL-1 alpha and beta administered in a phase I trial to patients with advanced cancer. J Immunother Emphasis Tumor Immunol. 1996;19:142-148.

32. Bedi O, Dhawan V, Sharma PL, Kumar P. Pleiotropic effects of statins: new therapeutic targets in drug design. Naunyn Schmiedebergs Arch Pharmacol. 2016;389(7):695-712.

33. Larsen CM, Faulenbach M, Vaag A, Vølund A, Ehses JA, Seifert B, Mandrup-Poulsen T, Donath MY. Interleukin-1-receptor antagonist in type 2 diabetes mellitus. N Engl J Med. 2007;356(15):1517-1526.

34. Ridker PM, Thuren T, Zalewski A, Libby P. Interleukin-1 $\beta$ inhibition and the prevention of recurrent cardiovascular events: rationale and design of the Canakinumab Anti-inflammatory Thrombosis Outcomes Study (CANTOS). Am Heart J. 2011;162(4):597-605.

35. Zhang J, Rudemiller NP, Patel MB, Karlovich NS, Wu M, McDonough AA, Griffiths R, Sparks MA, Jeffs AD, Crowley SD. Interleukin-1 receptor activation potentiates salt reabsorption in angiotensin II-induced hypertension via the NKCC2 co-transporter in the nephron. Cell Metab. 2016;23(2):360-368.

36. Sapolsky RM, Romero LM, Munck AU. How do glucocorticoids influence stress responses? Integrating permissive, suppressive, stimulatory, and preparative actions. Endocr Rev. 2000;21(1):55-89.

37. Jones TH, Kennedy RL. Cytokines and hypothalamic-pituitary function. Cytokine. 1993;5(6):531-538. 